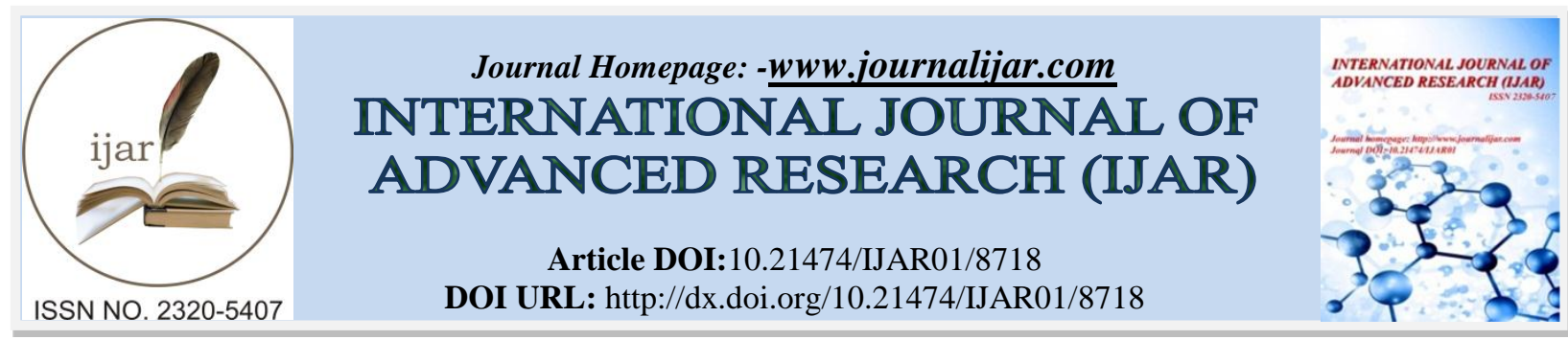

RESEARCH ARTICLE

\title{
MULTIPLE VENOUS ANEURYSM OF LOWER LIMB WITH DEEP VEIN THROMBOSIS: CAUSE OR COMPLICATION: A RARE CASE REPORT.
}

Arockia Sundari J J, Pinjala Ramakrishna, Sandeep Mahapatra, Naren Shetty, Puneeth Joopalli and Arumalla Anusha.

\section{Manuscript Info}

\section{Abstract}

\section{Manuscript History}

Received: 17 January 2019

Final Accepted: 19 February 2019

Published: March 2019

\section{Introduction:-}

Venous aneurysms most commony reported are primary popliteal aneurysms. Here we present a case of rarer presentation of symptomatic popliteal aneurysm and deep vein thrombosis with multiple short saphenous vein aneurysms.

\section{Case Report}

40 years old male, chronic smoker presented with swelling in the left calf, and posterior knee joint for 7 years, which rapidly increased in size with disabling pain for 2 months with no claudication, breathlessness or trauma.

Physical examination revealed soft swelling in the left popliteal fossa. It was associated with tenderness of calf muscle and distal palpable pulses. no hypertrophy of limb or gangrene was present. Venous colour doppler of left leg showed eccentric thrombosed saccular aneurysm involving lateral aspect of popliteal vein extending into saphenopopliteal junction and Short saphenous vein upto calf level with incompetent perforators.

Excision of venous malformation under GA along with thrombectomy of popliteal vein was done, and compression bandage applied. patient had uneventful post op.
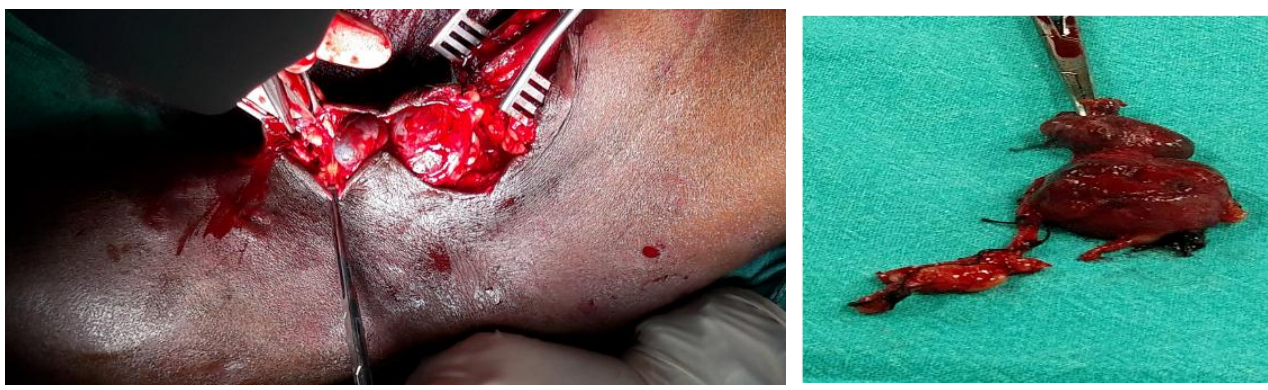

Macroscopic cut section of the mass showed intact venous wall and soft thrombus filled lumen. 
Literature review using pubmed, medline database search was done. 205 articles were on popliteal aneurysm, most of them being associated with pulmonary thromboembolism were retrieved. And less than 10 cases of popliteal aneurysm had, associated short saphenous vein aneurysm with deep vein thrombosis.

\section{Discussion:-}

Popliteal aneurysms with its subtle presentation and fatal complication needs to be attended to, by surgical resection with adequate anticoagulation, and treatment of complication.

venous aneurysms are characterized with occlusive fibrosis and outward remodelling with no known primary etiology.

Ultrasound with its noninvasive component becomes the first choice of investigation, needless to mention the importance of clinical acumen was vital for the diagnosis.

The case presented here is rare ${ }^{1,2}$, with its association with Deep vein thrombosis and extension into short saphenous vein ${ }^{3}$. surgical intervention along with anticoagulation has prevented the patient from its dreaded pulmonary complication ${ }^{4}$ and disability. Patient was advised compression bandage until the incompetent perforators were to be dealt at a later date.

\section{Conclusion:-}

Venous aneurysms poses an iceberg of complications, and need to be diagnosed as early as it could be prevented. Anticoagulation along with surgical intervention for prevention has been the treatment to stay.

\section{References:-}

1. Chen SI, Clouse WD, Bowser AN, Rasmussen TE. Superficial venous aneurysms of the small saphenous vein. J Vasc Surg. 2009 Sep;50(3):644-7

2. Draca P, Utikala P, Köcherb M, Cernab M, Kozakb J, Bachledaa P. Lesser saphenous vein aneurysm and popliteal vein aneurysm: Report of two cases and review of literature. Biomed Pap Med Fac Univ Palacky Olomouc Czech Repub. 2009, 153(4):289-292.

3. Ioannidis O, Varnalidis I, Alexandris K, Anastasiadou C, Megalopoulos A. Double primary venous aneurysm of the small saphenous vein. Ann Ital Chir. 2016 oct; 87.

4. Dorobisz AT, Korta K, Milnerowicz A, Iznerowicz A, Dorobisz TA. Venous aneurysm as a therapeutic problem: various management strategies in selected patients: our experience. Zentralbl Chir. 2012 Oct;137(5):472-7 